\title{
Implementation of Total Error Perception in the Analytical Method Validation for Quantification of Related Substance in Pharmaceutical Formulation
}

\author{
Islam Sofiqul*, Murugan V, Prema Kumari KB \\ Department of Pharmaceutical Chemistry, College of Pharmaceutical Sciences, Dayananda Sagar University, Bengaluru, Karnataka, INDIA.
}

\begin{abstract}
Objectives: This study is initiated to develop a simple and reproducible liquid chromatographic method with ultraviolet detection for the estimation of Sisomicin in Gentamicin pharmaceutical formulation by application of total error statistical tool. Methods: Gentamicin has a weak UV chromophore it is not possible to detect low levels of known related substance of gentamicin using a UV detector. Hence derivatization technique was applied to detect those substances. Chromatographic separation was accomplished by using Thermo scientific Hypersil Gold column $(150 \times 4.6 \mathrm{~mm})$ and $5 \mu \mathrm{m}$ particle size as stationary phase by isocratic elution with Methanol: Water: Glacial acetic acid: Sodium hexane sulfonate in the ratio 70:25:5:3\% v/v/ $\mathrm{v} / \mathrm{W}$ as mobile phase. Sisomicin was detected at $330 \mathrm{~nm}$ within $25 \mathrm{~min}$ with a flow rate of $0.5 \mathrm{~mL} / \mathrm{min}$. Results: Concurrent results were obtained in the developed analytical method based on total error measurement. Proposed method showed good linearity response ( $>0.995$ ) with limit of quantification at $0.007495 \mathrm{mg} / \mathrm{mL}, \%$ relative standard deviation less
\end{abstract}

than $1 \%$ in repeatability and \% recovery was found within 96 to $98 \%$ in accuracy. Accuracy profile result found within the range of $\pm 10 \%$ and risk profile $\pm 5 \%$ between the two set. Conclusion: This method can separate all the analogues of Gentamicin including known related substances. The finding demonstrated that method could be suitable for quantification of related substances in parental liquid dosage form.

Key words: Gentamicin, Ultra violet detection, Liquid chromatography, Related substance, Quantification.

Correspondence

Mr. Islam Sofiqul

College of Pharmaceutical Sciences, Dayananda Sagar University, Bengaluru-560078, Karnataka, INDIA.

Email: sofi59964@gmail.com

DOI: 10.5530/jyp.2021.13.25

\section{INTRODUCTION}

Gentamicin sulfate is a potent broad-spectrum aminoglycoside antibiotic which is active against Gram-positive and Gram-negative bacteria. Gentamicin sulfate is a mixture containing four major components, namely Gentamicin $\mathrm{C}_{1}$, Gentamicin $\mathrm{C}_{1 \mathrm{a}}$, Gentamicin $\mathrm{C}_{2}$, and Gentamicin $\mathrm{C}_{2 \mathrm{a}}$ Gentamicin originally obtained from the strain of Micromonospora purpurea ${ }^{1,2}$ by fermentation and they contain other known substances like Sisomicin. Sisomicin is considered as related substance which might obtained during the storage or manufacturing of Gentamicin. Aminoglycoside molecules are basic in nature, water-soluble and relatively stable. Chemical structure of Gentamicin is shown in Figure 1. All major components of Gentamicin and its related substance Sisomicin have weak UV absorbing chromophores. ${ }^{3}$ Owing to the lack of UV chromophores in molecular structure, the quantification of these molecules has always been challenging. Various liquid chromatographic detection techniques such as Refractive Index, Charged Aerosol Detector and Electrochemical Detection were used to quantify these substances. All these detection methods have some limitations for use. ${ }^{4} \mathrm{RI}$ detection slightly varies from gradient methods which are required to separate the analogue from its main components, CAD and ECD detectors are very sensitive to small changes in a specified temperature. ${ }^{5,6}$ Monitoring of known related substances in routine analysis will provide the exact measurement of the true value during manufacturing. ${ }^{7}$ Sensitivity and selectivity related problems occur while using liquid chromatographic technique coupled with tandem mass spectroscopy and fluorescence detector. ${ }^{8,9}$ However, this method is inferior in terms of reproducibility, separation and robustness. ${ }^{10}$ To counter all these challenges faced by conventional detectors an attempt was made to develop a derivatization technique with UV detector. Derivatization technique helps the substances to form a derivative and improve its physicochemical properties which can be used for the separation of the related substances from its original component. ${ }^{11}$ Derivatization technique makes the substances more UV active and improves the other indicators of chromatographic performance. ${ }^{12}$

As per the literature review, no such official liquid chromatographic techniques are available for the quantification of Sisomicin in this aminoglycoside's antibiotic by UV detection technique. Hence, the aim of this study was to develop a simple, precise, accurate liquid<smiles>CNC(C)C1CCC(N)C(OC2C(N)CC(N)C(OC3OCC(C)(O)C(NC)C3O)C2O)O1</smiles>

Figure 1: Chemical structure of Gentamicin. 
chromatographic method using UV detection to quantify the related substances present in Gentamicin.

\section{MATERIALS AND METHODS}

\section{Chemicals and Reagents}

HPLC grade of methanol and Sodium hexane sulfonate was supplied by Sigma Aldrich (Bangalore). Glacial acetic acid, boric acid and potassium hydroxide of ACS grade was procured from Merck (Bangalore). Orthophthalaldehyde (OPA) was procured from Sigma Aldrich (Bangalore). Milli-Q water was obtained from Milli-pore system. Gentamicin and Sisomicin were purchased from Sigma Aldrich (Bangalore).

\section{Instrumentation}

Waters e2695 Alliance HPLC system was used during the analysis. The HPLC system was equipped with a column compartment with temperature control and on-line degasser including UV detector. Data acquisition analysis and reporting were performed using Empower 3.0 software (Waters). Analysis was carried out using Thermo Scientific Hypersil Gold column having the dimensions 150 x $4.6 \mathrm{~mm}$ and $5 \mu \mathrm{m}$ particle size. This column produced well-separated peaks and considered as the suitable column to run for further analysis. Micropipette (Eppendroff), Analytical weighing balance (Metrohm, Model XP205 and XP26) and pH meter (Metrohm, Model 780) were used. The mobile phase (also used as diluent) was filtered under the vacuum through 0.45 $\mu \mathrm{m}$ membrane filters (Merck Millipore).

\section{Mobile Phase Selection}

Several mobile phase combinations were tested during optimization of the chromatographic condition. Various combinations of mobile phases such as methanol: water: acetic acid: sodium hexane sulfonate (70:25:5:5 $\mathrm{v} / \mathrm{v} / \mathrm{v} / \mathrm{w})$, methanol: water: acetic acid: sodium octane sulfonate (70:25:5:5 v/v/v/w), methanol: water: glacial acetic acid: sodium hexane sulfonate $(70: 25: 5: 4 \mathrm{v} / \mathrm{v} / \mathrm{v} / \mathrm{w})$ and methanol: water: glacial acetic acid: sodium hexane sulfonate $(70: 25: 5: 3 \mathrm{v} / \mathrm{v} / \mathrm{v} / \mathrm{w})$ were checked to improve the baseline of chromatogram.

It was observed that the clean baseline was observed in mobile phase combination of methanol: water: glacial acetic acid: sodium hexane sulfonate in the ratio $70: 25: 5: 3 \mathrm{v} / \mathrm{v} / \mathrm{v} / \mathrm{w}$. It might be due to the presence of less ionic buffer in the mobile phase combination.

\section{Analytical Column Selection}

Sisomicin and Gentamicin standard solution was injected in various column entities such as Waters Symmetry $\mathrm{C}_{18}(250 \mathrm{x} 4.6 \mathrm{~mm} ; 5 \mu)$, Phenomenex Luna $\mathrm{C}_{18}(250 \mathrm{x} 4.6 \mathrm{~mm} ; 5 \mu)$, Agilent Zorbax $\mathrm{C}_{18}(250$ x 4.6 $\mathrm{mm} ; 5 \mu)$ and Thermo Scientific Hypersil Gold $\mathrm{C}_{18}(150 \times 4.6 \mathrm{~mm} ; 5 \mu)$. Finally, it was found that Thermo Scientific hypersil Gold column was more suitable column for the separation and elution of Gentamicin and its related substances.

\section{Column Temperature}

Column temperature at $30^{\circ} \mathrm{C}$ was found to be more suitable for this chromatographic condition.

\section{Flow Rate and Injection Volume}

The flow rate of the mobile phase was considered as $0.5 \mathrm{ml} / \mathrm{min}$ during this chromatographic run.

Preliminary chromatographic condition was started without derivatization of the sample to detect the elution of the peaks by using various combinations of mobile phase with different analytical columns. But no peaks were eluted. Therefore, it was decided to derivatize the sample and inject the sample into suitable columns to improve the separation of the Gentamicin components and its related substance.

\section{Solution Preparation}

\section{Preparation of Standard Solution}

Gentamicin and Sisomicin stock solutions were prepared using $2 \mathrm{mg} / \mathrm{ml}$ and $0.5 \mathrm{mg} / \mathrm{ml}$ concentrations respectively.

Further, the respective stock solutions of Gentamicin and Sisomicin were diluted and standard solutions were prepared at the concentration level of $0.5 \mathrm{mg} / \mathrm{ml}$ and $0.0075 \mathrm{mg} / \mathrm{ml}$ respectively. All the dilution was made by using the diluent. Standard solution was considered as system suitability solution.

\section{Preparation of Sample Solution}

Sample solutions were prepared at $0.5 \mathrm{mg} / \mathrm{ml}$ concentration level and injected separately to identify any inherent known peak.

\section{Preparation of Linearity, Precision and Accuracy Solution}

Sisomicin was spiked into the sample concentration of Gentamicin and prepared at various concentration levels to perform these parameters. All solutions were prepared at various concentration levels of $0.0075 \mathrm{mg} /$ $\mathrm{ml}$ to $0.0225 \mathrm{mg} / \mathrm{ml}$ for Sisomicin. For each concentration of solution preparation, the required amount of Gentamicin and Sisomicin stock solutions were transferred into $25 \mathrm{~mL}$ volumetric flask and then $4.0 \mathrm{~mL}$ of OPA reagent and $5.0 \mathrm{~mL}$ of methanol were added and heated at $60^{\circ} \mathrm{C}$ for $15 \mathrm{~min}$. The final volume was made up to the mark with diluent. All solutions were stored at refrigerated condition and injected within $24 \mathrm{hr}$ of preparation.

\section{Method Development}

The Proposed method was designed by optimizing the chromatographic conditions by pertaining to various trial runs altering the mobile phase composition, ratio of mobile phase, column type and dimensions to attain symmetrical analyte peak in a short run time. Mobile phase combination of methanol: water: glacial acetic acid: sodium hexane sulfonate in the ratio $70: 25: 5: 3 \mathrm{v} / \mathrm{v} / \mathrm{v} / \mathrm{w}$ was found to be suitable combination to get

Table 1: Results for System suitability test.

\begin{tabular}{|c|c|c|c|c|c|}
\hline \multirow{2}{*}{ Acceptance Value } & \multicolumn{5}{|c|}{ Results } \\
\hline & C1 & C1A & $\mathrm{C} 2 \mathrm{~A}$ & Sisomicin & $\mathrm{C2}$ \\
\hline Theoretical plates should be NLT 2000 & 2875 & 6770 & 7000 & 6786 & 7916 \\
\hline Tailing Factor should be NMT $2.0^{\mathrm{a}}$ & 1.0 & 1.0 & 1.1 & 1.0 & 1.0 \\
\hline $\begin{array}{c}\% \text { RSD of six replicate injection should } \\
\text { be NMT } 5.0 \%^{\text {b }}\end{array}$ & 0.5 & 0.8 & 0.1 & 0.2 & 0.5 \\
\hline $\begin{array}{l}\text { Resolution Between Sisomicin peak and } \\
\text { adjacent peak should be NLT } 1.5^{c}\end{array}$ & & & 1.9 & & \\
\hline
\end{tabular}

a,b,c: decisive parameter for the suitability of the develop method. 
good resolution between the peaks. Hypersil Gold column found to be suitable column to separate each analyte. Each eluent was monitored at a wavelength of $330 \mathrm{~nm}$. Sisomicin peak was eluted on $13 \mathrm{~min}$. Chemical derivatization technique was employed to improve the chromatographic characteristics of each analyte.

\section{System Suitability}

System suitability is an integral part of analytical procedure. It is injected to check the correct performance of the system. System suitability was tested by injecting six replicates of system suitability solution. The \% Relative standard deviation of each peak area, tailing factor and theoretical plate count were determined for each components of gentamicin and its related substance peak. Individual standard solution injection of sisomicin was injected to check the retention time $\left(\mathrm{R}_{t}\right)$. System suitability results are presented in Table 1 .

\section{Method Validation}

Analytical method validation considered as a critical measurement especially for the quantitative methods in vision of regulatory aspect. Therefore, usages of statistical tool like total error concept provide an additional tool for assessing the performance of analytical methods. ${ }^{13}$

Validation solutions were prepared at triplicate and performed in two different days to show the applicability of total error approach.

Accuracy profile and uncertainty measurement used as additional tool to assess the performance of the proposed method. ${ }^{14}$

\section{Selectivity}

Selectivity is the ability of the method to identify the analyte present in the components that may be expected. Selectivity was designed in a chromatographic system for the analysis of the active compound without any interference from the blank.

\section{Precision/ Repeatability}

Precision is the closeness of the agreement between multiple sampling measurements of a homogeneous sample under the recommended circumstances. Intraday and Inter day studies assess the precision of the designed method. The total precision of the method was expressed as the relative standard deviation.

Linearity

The linearity of an analytical method is its ability to obtain the test results that are directly or through a well-defined mathematical transformation, proportional to the concentration of the analyte in the sample within a certain range. Linearity solutions were serially diluted from each stock solution of Gentamicin and Sisomicin to obtain various concentration levels covering QL to $150 \%$. The linearity covered the concentration range from $0.0075 \mathrm{mg} / \mathrm{mL}$ to $0.0225 \mathrm{mg} / \mathrm{mL}$.

\section{Accuracy and Trueness}

Accuracy refers to the closeness of agreement between the test results and the accepted reference value. Accuracy of the proposed method was assessed by calculating the recovery. To calculate the accuracy, Sisomicin was spiked to the test solution at LOQ level, 75\%,100\%, 125\% and 150 $\%$ level. Each solutions were tested for three times and calculated the average recovery at each level.

\section{Limit of Quantification (LOQ) and Limit of Detection (LOD)}

LOQ was estimated by checking the signal to Noise $(\mathrm{S} / \mathrm{N})$ at the lowest concentration level.
Sensitivity of the method determines how capable is the method for detecting the lowest possible concentration of analyte.

LOD is the lowest amount of analyte in a sample that can be detected, but not necessarily quantitated. LOD concentration for sisomicin was established by identifying the concentration which gives signal to noise ratio of about 3 .

\section{Robustness}

According to the $\mathrm{ICH}$, the robustness of an analytical method is its ability to withstand small but deliberate changes in the experimental variables. In this study, the robustness was evaluated by an experimental design examining the system suitability solution by simultaneous influence on varied column temperature condition $\left(30 \pm 2^{\circ} \mathrm{C}\right)$.

\section{RESULTS}

Gentamicin is a potent broad-spectrum aminoglycoside antibiotic which is active against Gram-positive and Gram-negative bacteria. Gentamicin was used for treatment of respiratory, gastrointestinal and urogenital infections. Aminoglycoside antibiotic assays, including those for gentamicin sulfate, are frequently microbial assays. These assays measure activity; however, they cannot quantify impurities or determine content of specific compounds in a product. For this reason, chromatographic techniques are often favored for improved specificity and the ability to differentiate impurities that have the potential for both antibiotic activity and unintended side effects. Due to similar structure separation of the individual components within gentamicin sulfate potentially difficult. Aminoglycoside antibiotics do not contain chromophores, making UV detection insensitive. To compensate for this lack of a chromophore, derivatization techniques have been developed. After sample derivatization, these components are separated on a $\mathrm{C}_{18}$ reversed-phase column and can be quantified by UV detection. A new method was developed by using derivatization technique to quantify those aminoglycosides molecules. Developed method was validated using total error measurement and accuracy profiles as a decision tool. Contemporaneous results were achieved in the developed and optimized method. The main challenge in the development of the chromatographic method determination was achieving the chromatographic separation of the Sisomicin peak and components of gentamicin. The separation was achieved by optimization of usages of different mobile phase and utilization of different stationary phase. No interference peak was observed at the retention time of Sisomicin peak and components of gentamicin peak from diluent and mobile phase injections. The method was found to be linearity with a correlation value more than 0.995 over the range of $0.007495 \mathrm{mg} / \mathrm{ml}-0.0225 \mathrm{mg} / \mathrm{ml}$. The average recovery results were within $96 \%-98 \%$ for the developed method with \% RSD less than $5 \%$.

\section{DISCUSSION}

Aminoglycosides are a group of widely used broad spectrum antibiotics with many desirable properties for the treatment of life-threatening infections. They act primarily by impairing bacterial protein synthesis through binding to prokaryotic ribosomes. ${ }^{15}$ Gentamicin sulphate is an aminoglycoside antibiotic formulated by fermentation of Micromonospora purpurea. It is a mixture of compounds, the major components are gentamicin $\mathrm{C} 1, \mathrm{C} 1 \mathrm{a}, \mathrm{C} 2, \mathrm{C} 2 \mathrm{a}$ and a minor quantity of related substances like sisomicin, which are formed in small amounts during fermentation or as degradation substance. ${ }^{16}$ Aminoglycoside molecules are high polar, non-volatility and lacking the presence of chromophore in their structure which makes the analysis quite problematic. Structure of Gentamicin and its related substance are closely related to each other and do not possess UV absorbing 
chromophores which leads to the challenging quantification. Proposed chromatographic method can separate the analogue of Gentamicin and its related substances. The quantification was carried out using isocratic elution on an analytical column (Make: Thermo Scientific Hypersil Gold (150 X $4.6 \mathrm{~mm} ; 5 \mu \mathrm{m}$ particle size) at a flow rate of 0.5 $\mathrm{ml} / \mathrm{min}$ and column temperature at $30^{\circ} \mathrm{C}$. The method was successfully validated under optimized conditions using the e-Noval statistical tool with acceptance criteria of the $95 \%$ confidence interval (5\% risk) with an accuracy profile of $\pm 10 \%$. This provided a greater confidence in the performance of methods. To prove the Selectivity of the method, an injection of diluent along with System Suitability solution and Sisomicin standard solution was injected. No interference peak was observed at the retention time of components of Gentamicin and Sisomicin. An overlay chromatogram of blank and system suitability injection presented in Figure 2. Method repeatability was determined using the six replicates injection at $100 \%$ of the test concentration $(0.0150 \mathrm{mg} / \mathrm{ml})$. The total precision of the method was expressed as the relative standard deviation. Precision and Intermediate precision results are presented in Table 2. RSD value of both intraday and intraday analysis was less than 5\% which is considered as acceptable value. Linearity covered the concentration range from $0.0075 \mathrm{mg} / \mathrm{ml}$ to $0.0225 \mathrm{mg} / \mathrm{ml}$. Then linearity was evaluated to calculate the coefficient correlation, slope and intercept. Linearity results are presented in Table 3. Linearity profile graph are plotted in Figure 3. Correlation coefficient value more than 0.995 is considered as the evidence of an acceptable value for the data obtained from regression

Table 2: Results for Precision and Intermediate precision.

\begin{tabular}{cccc}
$\begin{array}{c}\text { Concentration } \\
\text { level }\end{array}$ & $\begin{array}{c}\text { Mean introduced } \\
\text { concentration }(\mathrm{mg} / \\
\mathrm{mL})^{\mathrm{a}}\end{array}$ & $\begin{array}{c}\text { Repeatability } \\
\text { (RSD\%) }\end{array}$ & $\begin{array}{c}\text { Intermediate } \\
\text { precision } \\
\text { (RSD\%) }\end{array}$ \\
\hline 1.0 & 0.007495 & 0.01541 & 0.2122 \\
2.0 & 0.01126 & 0.03209 & 0.1568 \\
3.0 & 0.01501 & 0.02721 & 0.3473 \\
4.0 & 0.01877 & 0.06153 & 0.06330 \\
5.0 & 0.02251 & 0.06071 & 0.06071 \\
\hline
\end{tabular}

a. concentration of sisomicin spike to test solution

\%RSD: Percentage of Relative Standard Deviation.

Table 3: Results for Linearity.

\begin{tabular}{ccccc}
\hline Intercept & Slope & $\begin{array}{c}\text { Correlation Co- } \\
\text { efficient }\end{array}$ & $\begin{array}{c}\text { Regression Co- } \\
\text { efficient }\end{array}$ & RSS \\
\hline-0.00002524 & 0.9781 & 0.9999 & 0.9999 & 0.00000009 \\
\hline
\end{tabular}

RSS: Residual sum of Square

Table 4: Results for Accuracy and Trueness.

\begin{tabular}{ccccc}
\hline $\begin{array}{c}\text { Mean } \\
\begin{array}{c}\text { Concentration* } \\
(\mathrm{mg} / \mathrm{mL})\end{array}\end{array}$ & $\begin{array}{c}\text { Absolute } \\
\text { bias }^{\#}\end{array}$ & $\begin{array}{c}\text { Relative } \\
\text { bias }^{\#}\end{array}$ & Recovery & $\begin{array}{c}95 \% \\
\text { Confidence } \\
\text { Interval of } \\
\text { Recovery\# }\end{array}$ \\
\hline 0.007495 & -0.0002300 & $-3.069 \%$ & $96.93 \%$ & {$[96.76,97.10]$} \\
0.01126 & -0.0002121 & $-1.884 \%$ & $98.12 \%$ & {$[97.99,98.24]$} \\
0.01501 & -0.0003967 & $-2.644 \%$ & $97.36 \%$ & {$[97.07,97.64]$} \\
0.01877 & -0.0003683 & $-1.963 \%$ & $98.04 \%$ & {$[97.97,98.10]$} \\
0.02251 & -0.0005633 & $-2.503 \%$ & $97.50 \%$ & {$[97.43,97.56]$} \\
\hline
\end{tabular}

${ }^{*}$ Mean of 02 determination.

\#parameter assessing statical e-novel concept. line. To calculate the accuracy, Sisomicin was spiked to the test solution at LOQ level, 75\%, 100\%, 125\% and $150 \%$ level. Each solutions were tested for three times and calculated the average recovery at each level. The recovery of Sisomicin was found within $90-110 \%$. \% of risk at each level were presented in Table 5. Limit of Quantification (LOQ) level was considered as $0.0075 \mathrm{mg} / \mathrm{mL}$ and Signal-to-noise (S/N) ratio at LOQ level were presented in Table 6. System suitability solution was injected by simultaneous influence on varied column temperature condition and results are summarized in Table 7 and 8. Results are found within

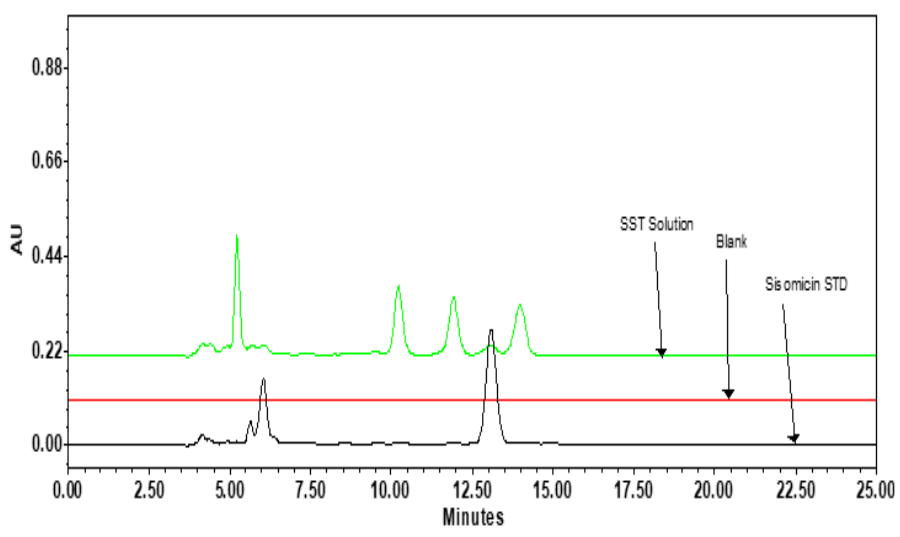

Figure 2: Zoomed Overlay chromatogram of Blank, SST Solution and Sisomicin Standard solution.

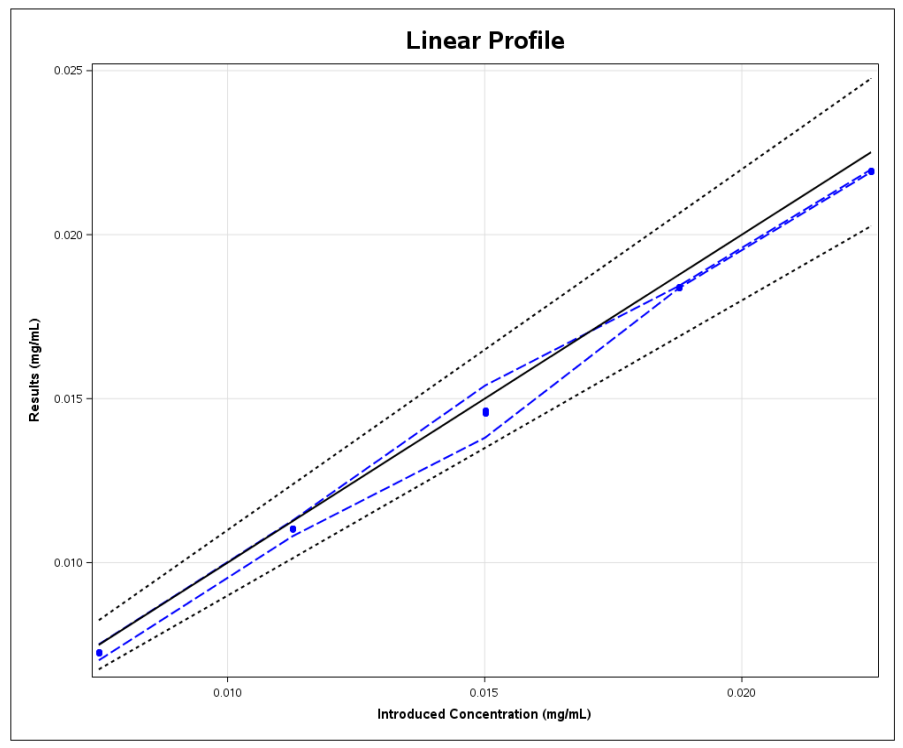

Figure 3: Linearity profile graph of Sisomicin.

Table 5: \% of risk at each level.

\begin{tabular}{ccc}
\hline Concentration level & $\begin{array}{c}\text { Beta-expectation } \\
\text { tolerance limits }(\mathrm{mg} / \\
\mathrm{mL})^{\#}\end{array}$ & Risk\# \\
\hline 1.0 & {$[0.007022,0.007508]$} & $1.782 \%$ \\
2.0 & {$[0.01080,0.01128]$} & $1.019 \%$ \\
3.0 & {$[0.01381,0.01540]$} & $2.840 \%$ \\
4.0 & {$[0.01836,0.01843]$} & $0.00000081 \%$ \\
5.0 & {$[0.02191,0.02199]$} & $0.00000032 \%$ \\
\hline
\end{tabular}

\#parameter assessing statistical e-novel concept. 
Table 6: Results for Limit of quantification.

\begin{tabular}{ccc}
\hline Related substances & Concentration $^{\text {a }}$ & Signal to Noise \\
\hline Sisomicin & $0.007495 \mathrm{mg} / \mathrm{mL}$ & 20 \\
\hline
\end{tabular}

${ }^{a}$ : Lowest concentration for limit of quantification analysis.

Table 7: Results for System suitability test at low column temperature $\left(28^{\circ} \mathrm{C}\right)$.

\begin{tabular}{cccccc}
\hline & \multicolumn{5}{c}{ Results } \\
\cline { 2 - 6 } Acceptance Value & C1 & C1A & C2A & Sisomicin & C2 \\
\hline $\begin{array}{c}\text { Theoretical plates should be } \\
\text { NLT 2000 }\end{array}$ & 3256 & 7870 & 7896 & 6658 & 8936 \\
$\begin{array}{c}\text { Tailing Factor should be } \\
\text { NMT 2.0 }\end{array}$ & 1.0 & 1.0 & 1.1 & 1.0 & 1.0 \\
$\begin{array}{c}\text { \% RSD of six replicate } \\
\text { injection should be NMT } \\
5.0 \%^{\mathrm{b}}\end{array}$ & 0.7 & 0.9 & 0.3 & 0.5 & 0.6 \\
$\begin{array}{c}\text { Resolution Between } \\
\text { Sisomicin peak and adjacent } \\
\text { peak should be NLT 1.5 }\end{array}$ & & & & & \\
\hline
\end{tabular}

a,b,c: decisive parameter for the suitability of the develop method.

Table 8: Results for System suitability test at low column temperature $\left(32^{\circ} \mathrm{C}\right)$.

\begin{tabular}{|cccccc}
\hline \multirow{2}{*}{ Acceptance Value } & \multicolumn{5}{c}{ Results } \\
\cline { 2 - 6 } & C1 & C1A & C2A & Sisomicin & C2 \\
\hline $\begin{array}{c}\text { Theoretical plates should be } \\
\text { NLT 2000 }\end{array}$ & 3658 & 7790 & 7806 & 7958 & 8436 \\
$\begin{array}{c}\text { Tailing Factor should be } \\
\text { NMT 2.0 }\end{array}$ & 1.0 & 1.0 & 1.1 & 1.0 & 1.0 \\
$\begin{array}{c}\text { \% RSD of six replicate } \\
\text { injection should be NMT } \\
\text { 5.0\% }\end{array}$ & 0.7 & 0.5 & 0.5 & 0.4 & 0.3 \\
$\begin{array}{c}\text { Resolution Between } \\
\text { Sisomicin peak and adjacent } \\
\text { peak should be NLT 1.5 }\end{array}$ & & & & & \\
\hline
\end{tabular}

a,b,c: decisive parameter for the suitability of the develop method.

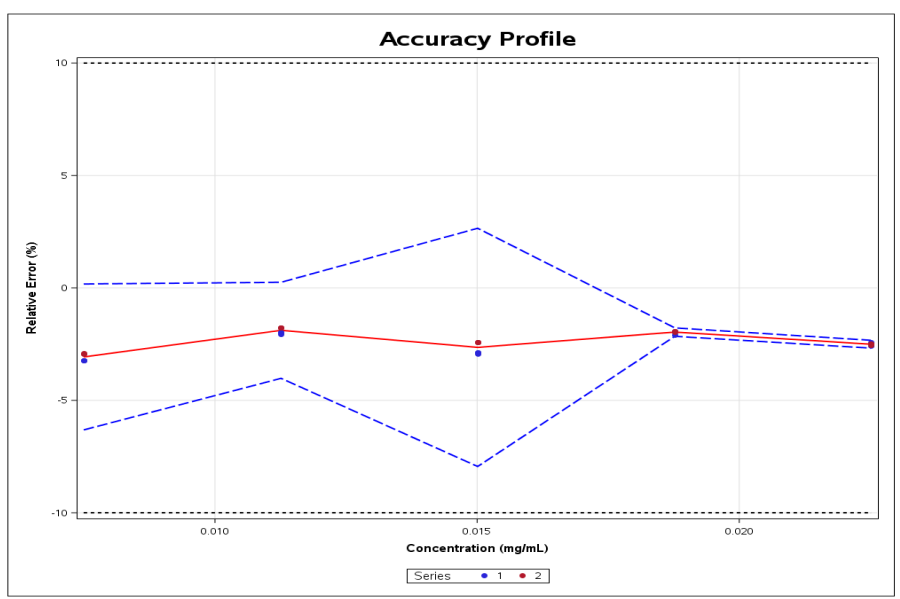

Figure 4: Accuracy profile for Sisomicin.

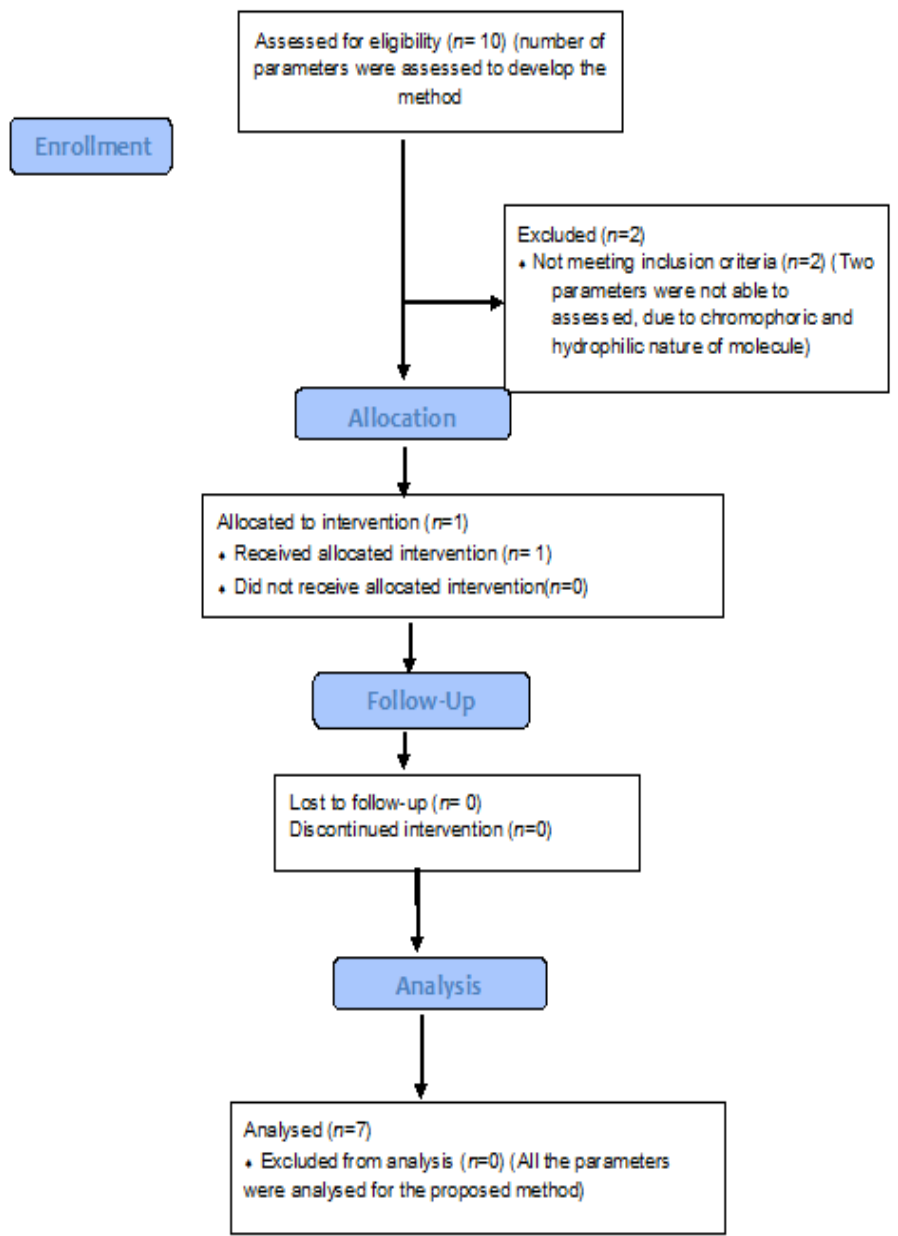

\section{Consort Flow Chart}

the acceptable limit. The results of the validation were considered satisfactory. Therefore, it can be concluded that the accuracy profile results are within $\pm 10 \%$ (limit) for Sisomicin as shown in Figure 4 . The results of the predictive interval (\%) at a risk level of $5 \%$ in the related substance range were less than 3\% (limit 5\%). The average recovery results were within $96.6 \%$ to $98 \%$ as shown in Table 4 . The precision results were also satisfactory, the results of maximum repeatability (\% $\mathrm{RSDRe})=0.06 \%$ and therefore, the maximum intermediate precision (\% RSDIP) $=0.15 \%$. The linearity correlation coefficient $(r)$ was found to be greater than 0.99 for Sisomicin peak. Linearity graph shows excellent corelation between the theoretical and experimental concentration value. No interference peaks were observed at the retention time of any main interested peak. Figure 2 shows that the method is specific. Robustness results demonstrates that the developed method is robust.

\section{CONCLUSION}

A selective, sensitive and simple HPLC-UV method was developed and validated for the estimation of Sisomicin in Gentamicin formulation. The application of total error concept and excellence of accuracy profile results proved the method performance and their suitability for use in quality control department. As the analyte of interest lacks the chromophore group in their chemical structure, their detection and quantification by the conventional UV detector with simple derivatization procedure is found to be suitable for regular testing in pharmaceutical formulations. 


\section{ACKNOWLEDGEMENT}

The authors are thankful to the College of Pharmaceutical Science, Bangalore for providing the necessary support to carry out the research work.

\section{CONFLICT OF INTEREST}

The authors declare no conflict of interest.

\section{ABBREVIATIONS}

ACS: American Chemical Society; UV: Ultra Violet; HPLC: High Performance Liquid Chromatography; NMT: Not More Than; NLT: Not Less Than, SST: System suitability Test, RSS: Residual sum of square, LOQ: Limit of Quantification; RI: Refractive Index; CAD: Charged Aerosol Detector; ECD: Electrochemical Detection; ICH: International Council for Harmonization; OPA: Ortho-phthalaldehyde; RSD: Relative Standard deviation; LOD: Limit of detection.

\section{REFERENCES}

1. International Conference on Harmonization $(\mathrm{ICH})$, Validation of Analytical procedure: Text and Methodology Q2 (R1). Geneva. 2005.

2. Ghinami C, Giuliani V, Menarini A, Abballe F, Travaini S. Electrochemical detection of tobramycin or gentamicin according to the European Pharmacopoeia Analytical method. J Chr A. 2007;1139(1):53-6.

3. Hoogmarten J, Adams E, Zhang Y, Ola G. Comparison of liquid chromatographic methods with direct detection for the analysis of gentamicin. J Pharm Biomed Anal. 2007;45(2):257-62

4. Soliven A, Haider A, Tam J. A simplified guide for charged aerosol detection of non chromophoric substances analytical method development and validation for the HPLC assay of aerosol particles size distribution for amikacin. J Pharm
Biomed Anal. 2007;143:68-76.

5. Manyanga $V$, Grishina O, Yun Z, Hoogmartens J, Adams E. Improved liquid chromatographic method with pulsed electrochemical detection for the analysis of gentamicin. J Chr A. 2008;1189 (1):347-54.

6. Grahek R, KraljZ. Identification of gentamicin impurities by liquid chromatography tandem mass spectrometry. J Pharm Biomed Anal. 2009;50(5):1037-43.

7. Gibelin N, Dupont D, Rozet E. Use of Total Error concept in the validation of viral activity in cell culture. J Chr B. 2009;23(1):2407-11.

8. Joseph A, Rustum A. Development and validation of a RP-HPLC method for the determination of gentamicin sulfate and its related substances in a pharmaceutical cream using a short pentafluorophenyl column and charged aerosol detector. J. Pharm Biomedi Anal. 2010;51(3):521-31.

9. Kuehl J, De S, Eppler B, Marsters J, Matthew L. Development and Validation of an HPLC assay for dual detection of Gentamicin sulfate and Leucine from a Novel dry powder for inhalation. J Anal Bio Anal Techniques. 2011;3:3-6.

10. Laki M, Ludanyi K, Hajdu M, Zahar A. Determination of Gentamicin released from orthopaedic carrier system by a Novel HPLC method. J Chr Sci. 2011:49(3):177-82

11. Prcetic K, Servenak RC. Development and validation of liquid chromatography tandem mass spectroscopy methods for the determination of gentamicin lincomycin and spectinomycin in the presence of impurities in Pharmaceutical formulations. J Pharm Biomed Anal. 2011;56(4):736-42.

12. Bart B, Shengyun $H$, Kartarzyna W, Erwin A et al. Assay development for aminoglycosides by HPLC with Direct UV detection. J Chr Sci. 2017;55(3):197204. DOI: 10.1093/chromsci/bmw169

13. Yurong H, Qingefng F, Sunliang S, Yaozuo. Determination of the content of Sisomicin and sodium chroride injection by rp-HPLC. 2018; 49(6):695-98.

14. Freneil B, John A etal. Rapid determination of aminoglycosides in Pharmaceutical preparations by electrospray ionization mass spectroscopy. J Ana Sci and Tech. 2020;11(2):1-11. DOI: 10.1186/s40543-019-0202-4.

15. Krause KM, Serio AW, Kane TR, Connolly LE. Aminoglycosides: An Overview Cold Spring Harb Perspect Med. 2016;6(6):a027029. DOI: 10.1101/cshperspect. a027029.

16. Oosterhuis WP, Theodorsson E. Total error vs. measurement uncertainty: revolution or evolution? Clin Chem Lab Med. 2016 Feb;54(2):235-9. doi: 10.1515/cclm-2015-0997.

Article History: Submission Date : 03-02-2021 ; Revised Date : 14-03-2021; Acceptance Date : 04-05-2021.

Cite this article: Sofiqul I, Murugan V, PremaKumari KB. Implementation of Total Error Perception in the Analytical Method Validation for Quantification of Related Substance in Pharmaceutical Formulation. JYoung Pharm. 2021;13(2):118-23. 